\title{
Clerical Aptitude In Library Employment
}

By EUGENE N. SALMON

AL THE BASIC operations and many of
the more complex ones in a library
depend fundamentally upon clerical ap-
titude. Clerical aptitude is necessary in
shelving books, in filing various types of
cards, in searching for missing books, in
using catalogs and indexes, and in revis-
ing slipping or typing or cataloging-
indeed in almost every operation re-
quired in a library. The clerical aptitude
required in performing any of these rou-
tine operations with speed and accuracy
can be divided into two separate abili-
ties: number differentiation and name (verbal) differentiation. Some people have equal or almost equal ability in these two areas; others show considerable differences because of variations in mathematical and verbal skills.

Since this special aptitude is used in some degree by every person working in a library, its measurement should be considered carefully by library administrators. A clerical aptitude test could be included in a battery of employment tests, and its results would indicate to the employer the applicant's ability in a vital area. It is wise not to hire a catalog filer or stack attendant low in clerical aptitude. Even though a certain amount of ineptitude can be overcome by intelligence, interest, and care, an employee without the necessary aptitude for his job tends to become dissatisfied as well as inaccurate.

This basic aptitude, like most others, cannot be acquired by an adult. Since no amount of study or practice would result in significant improvement, an applicant need not prepare for the test, and it can be given without advance notice. If the library is connected with
Mr. Salmon is on leave from his position as Head Circulation Librarian, University of Oregon. He is presently Head of Technical Information Services of the Library Technology Project at ALA headquarters.

a city or county government having a personnel division, or with a college or university which has a testing department, the problem of administering the test is solved. Otherwise, the library must do its own testing, and, therefore, the test should be simple to administer, score, and interpret, and should be inexpensive.

\section{The Test}

Such a test is available-the Minnesota Clerical Test. This test has simple instructions, requires only fifteen minutes to administer, and can be scored easily, with the results available in a few minutes. It measures both number and verbal clerical aptitude, with a minimum of variable factors. Applicants unfamiliar with the Roman alphabet, such as Asian students, may have some difficulties with the verbal portion of the test. This would indicate to the library that such persons would not be efficiently employed in filing catalog cards or charge cards by author. The arabic numerals used in the numbers section seldom prove to be a stumbling block, however.

Copies of this test, complete with scoring key and manual, cost as little as 7 cents each ${ }^{1}$-a modest sum compared to

1 The test may be purchased from Psychological Corporation, 304 East 45 th Street, New York 17, N. Y. $A$ specimen set, including manual and key, can be purchased for 50 cents; a group of twenty five sets of tests, including manual and key, sells for $\$ 2.00$; one hundred tests cost $\$ 7.00$. 
the savings to the library when the best qualified applicants are employed.

\section{Procedure and Scoring}

If a number of applicants are to be tested, it is advisable to test them together in order to minimize variables and the test administrator's time.

The Minnesota Clerical Test has two sections: numbers and names. Each has two hundred "problems" consisting, respectively, of pairs of numbers and pairs of names (of a company, an individual, etc.). The applicant is instructed to place a check on a line between each pair if the items are identical and to leave it blank if the items do not match exactly. $\mathrm{He}$ is advised that he is allowed eight minutes to work on the numbers (first part) and seven minutes to work on the names (second part), and that there will be a pause between the two. $\mathrm{He}$ is instructed to draw a line under the last pair of items completed in each section. That is all there is to giving the test.

To score, a key is compared with the check marks. The "number right" is the total number completed minus the "number wrong." The "number wrong" is then entered in the scoring space and is subtracted from the "number right," to obtain a raw score for each part.

Even though inaccuracy is doubly punished by this method, an applicant can usually obtain a higher score by favoring speed. This suggests a principal limitation of this test: accuracy may be subordinated to speed. In a library, accuracy is primary because of great numbers of items that must be readily available. Rapid shelving of books or filing of cards is futile if the books or cards cannot be located because of errors. However, the emphasis on speed can be compensated for in the interpretation of the score, an interpretation each employer must make if the test is to be used intelligently.

\section{Analysis of Validity Test}

Experience with this test has been gained over a five-year period through the testing of student assistant applicants for work in the circulation department of the University of Oregon Library. The purpose in testing student assistants was simply to determine which of the numerous applicants had the best prediction of success at the routine clerical level to do the work accurately and rapidly. Naturally, other factors were taken into account, and an interview disclosed the applicant's personality, general intelligence, work interest, and other factors considered pertinent to employment.

In order to set up the testing program initially, a consultation was held with the then director of admissions of the University of Oregon. The consultation led to the selection of the Minnesota Clerical Test as the most practical and inexpensive test for this specific aptitude. The head librarian gave his consent to the installation of the program, and a validity test was arranged. All the students then working in the department were asked to take the test, with the understanding that the results would not affect their status. Prior to the administration of the test, each of the three supervisors was asked to rate his employees as "high," "average," or "low" in their ability to do the work assigned. Initiative, dependability, interest, and general value to the department served as criteria for these ratings. Then the test scores and the work ratings were correlated, in an attempt to determine the validity of this test in our own situation.

Of a total of seventeen students employed in the circulation department, two did not take the test, and one, having misunderstood the instructions, completed only half the test. Of the six (two from each of the three areas of the department) rated "high" by their respec- 
tive supervisors, two scored in the upper third, two in the middle third, and two in the lower third. Of the nine rated "average," two scored in the upper third, four in the middle third, and one in the lower third. Rated "low" were one boy and one girl. They both scored in the lower third. By selecting the top two thirds of the scores, a total of 75 per cent would have been satisfactory employees, and there would have been 100 per cent rejection of unsatisfactory applicants.

A scale which would ignore the disparity between men's and women's potentials was needed because the sex of the applicant was for our purposes irrelevant, and because many more females than males make application. With the assistance of a graduate psychology student, a method of analyzing scores was developed as follows: the percentile scales were disregarded, and instead the raw scores for the two parts of the test were added together. Based on the test results given above (admittedly a very small sample), a total raw score of 230 was established as a base index.

Subsequent experience with over 200 of these tests has shown 230 to be a valid base score. One may consider under 200 to be a low average, (and would rarely hire anyone scoring below that) and over 260 to be a high average. Any score over 300 is high, and anyone scoring 350 or more out of the possible 400 will become a superior clerical worker. It is rare, however, for anyone to complete either part, much less both parts, of the test. Worth noting is that when the score is exceptionally high there will be few errors, rarely more than one or two. Low or average scores may also have few errors or may have total errors running into the tens and twenties. However, the great majority of applicants score somewhere between the two extremes. In attempting to make a selection from this average group, an employer must take into account all the qualities of an applicant and call upon his own experi- ence and judgment in order to get a total impression of the prospective employee.

\section{INTERPRETATION AND APPLICATION}

In the interpretation of the test, an employer can compare one applicant's score with the scores of all others who have taken the test at that time, or with the scores of all those who have previously taken the test. For example, if the highest score of a given group is a low score by normal standards, it would be gambling to hire that person, much less any of the others who scored even lower. In such a case, the psychometrist should be consulted to determine that test timing and other test conditions were all properly met.

As an aid to interpretation, there are available different norms worked out on a national or regional average, with percentiles for both men and women. Since women, as a group, score higher than men in this test, they will have lower percentile ratings than men for comparable scores. Experience in the use of this test will enable an employer to determine which of the various scales is the most applicable in his own situation.

The use of the base number may be preferred, especially when the sex of the employee is not a factor, or the percentile scale method may be preferred if the applicants are all of the same sex or if only one sex is being considered for the position (such as stack superintendent). But if percentiles are used, a point to remember is that a male will show a higher percentile rating for less aptitude than will a female, and comparing their percentiles may be misleading.

Not only must the total score in each part and the total of those scores (or the percentile ratings, if that method is used) be considered, but also the number of errors on each part. Here the speedaccuracy factor can be somewhat evened, for if a person has a high score and few errors, there is no need to worry about 
his accuracy; if he has a low score and many errors he is not only slow but inaccurate, and it is obvious what would happen if he tried to speed up. But it is the average score with the average number of errors that makes the choice difficult. It is fruitless to try to analyze the cause of the errors (omissions, transpositions, etc.); it is the total number of errors on each part that counts.

Although the two parts of the test supplement each other and both the aptitudes they measure will be used on the job, if the position is primarily alphabetical filing (as in the public catalog), the name section of the test logically will be weighted more heavily in selecting an employee; if the job calls for charge card filing by call number, the number section of the test would be more significant.

For example, in the University of Oregon Library circulation department, students are first employed for work in the stacks and then progress to either the main circulation desk or the reserve book room desk. The two desks have a different orientation: at the main circulation desk, call numbers are used as identification symbols; at the reserve book desk, names are used almost exclusively-author, title, department, faculty. Thus, employing a person who has a low score or has a large number of errors on the number part for the main circulation desk would be unwise. It is in use such as this that the test can prove valuable even when the applicant's score is average.

Also to be considered is the instance of an applicant's invalidating the tests by misunderstanding the directions. Experience with over two hundred tests has revealed only two people who misunderstood the simple instructions and continued on the number test when they were supposed to go on to the name test after the pause. Since these two people had pitifully low scores even though they had spent fifteen minutes on just one part of the test, it seemed fair to assume that they lacked both clerical aptitude and the ability to follow directions. The only significance in these cases is that an employer is made aware that he has an applicant with a tendency not to pay close attention to detail. This information could be valuable if the applicant were hired.

Apparently there is a low, almost nonexistent, correlation between clerical aptitude and intelligence. A person's intelligence cannot be determined from this test nor, knowing his intelligence in advance, can his clerical ability be predicted. The fact that all the tests given here have been to university students and that the scores vary more widely than I.Q. scores would vary is some evidence for this statement. If an employer has a clerical job that requires exceptional intelligence, he should look elsewhere for a measurement of applicants' abilities. This test measures only clerical aptitude and, as such, should not be asked to do anything more, nor should it be the sole basis for hiring.

This test can be used in a general way other than as an employment test. It would be valid as one in a battery of tests for library school entrance. There may be many who feel that this latter suggestion is invalid in the case of professional librarians, but I believe those who have the most difficulty orienting themselves are the ones who have diffculty in routine clerical duties, such as filing, finding books in the stacks, and proofreading letters. Certainly a person should not be eliminated from consideration as a professional librarian because he has low clerical aptitude, but this deficiency should be considered by the applicant, the library school, and the potential employer as something which will have to be overcome.

In fact, part of this test's value is that it provides a forewarning that enables the employee to forearm himself. If he

(Continued on page 322) 
nature and potential use of the items listed. Periodical articles and critical reviews are included, and for the more important monographs tables of contents are often given. There are indexes of main entries and of subjects.-J.N.W.

\section{Classical Antiquities}

Akademiia Nauk SSSR. Institut Istorii. Drevniaia Gretsiia i drevnii Rim; bibliograflcheskii ukazatel' izdanii vyshedshikh v SSSR 1895-1959. Sostavitel' A. I. Voronkov. Moskva, 1961. 522p. 4 rubles, 38 kopeks.

This is a classified bibliography of studies published in pre-Revolutionary Russia and in the Soviet Union between 1895 and 1959, in the Russian, Greek, or Latin languages. Some Byzantine and mediaeval materials are listed when they relate to authors of antiquity, transmitting texts. All phases of
Greek and Roman culture are included, as well as the history of the teaching of classical subjects. There is an index for modern authors, translators, editors, and reviewers.E.B.

The New Century Classical Handbook, ed. by Catherine B. Avery. Editorial consultant, Jotham Johnson. New York, Appleton-Century-Crofts, 1962. 1162p. illus. $\$ 15$.

Designed for the general reader and the student, this work presents in one alphabet much clear and concise information on people (real and imaginary), gods, legends, places, literary titles, allusions, etc., connected with the classical world. (There are very few articles under common nouns.) Sketches vary in length from a few lines to several pages, none signed; nor are there any bibliographies or cross references. Pronunciation is indicated. There are many handsome plates, well reproduced, but placed with no relation to the text and not indexed.-J.N.W.

\section{Clerical Aptitude ...}

(Continued from page 314)

has scored high in the test he can be told that if he takes it slowly at first in order to learn the routine, speed will come naturally. If he has scored below average and is hired, he should be told honestly that he need to be careful in his work since he will be prone to error if he attempts to speed up beyond his ability.

In summary, the measurement of the clerical aptitude of an applicant can enable an administrator to avoid the expense, frustration, and loss of efficiency that will result from hiring unqualified personnel. Use of the Minnesota Clerical Test will provide such information as verbal and number aptitude and the relative speed and accuracy of an applicant in each area. The inexpensiveness, the simplicity of administration and scor- ing, and the numerous aids to interpretation make this test an excellent instrument for the detailed measurement of clerical aptitude.

However, as is the case with most tests of this type, its usefulness depends ultimately on the experience and judgment of the person interpreting it. Only in the cases of very high and very low scores can an administrator give this test extra weight in his final decision. As one's experience in using the test grows, its usefulness will increase and refinements in usage will undoubtedly be discovered by the more imaginative. But even at the outset, the negative value of the test is high. Almost without fail, it will provide the information without which a hopelessly clerically inept person might have been hired. 